\title{
Heterologous Expression of Rhizobial CelC2 Cellulase Impairs Symbiotic Signaling and Nodulation in Medicago truncatula
}

\author{
Marta Robledo, ${ }^{1,2}$ Esther Menéndez, ${ }^{1}$ Jose Ignacio Jiménez-Zurdo, ${ }^{2}$ Raúl Rivas, ${ }^{1}$ Encarna Velázquez, ${ }^{1}$ \\ Eustoquio Martínez-Molina, ${ }^{1}$ Giles Oldroyd, ${ }^{3}$ and Pedro F. Mateos ${ }^{1,+}$ \\ ${ }^{1}$ Departamento de Microbiología y Genética, Centro Hispano-Luso de Investigaciones Agrarias, Universidad de Salamanca, \\ Unidad Asociada CSIC/USAL, Spain; ${ }^{2}$ Estación Experimental del Zaidín, CSIC, Granada, Spain; and ${ }^{3}$ Department of Cell and \\ Development Biology, John Innes Centre, Norwich, U.K.
}

Accepted 12 January 2018.

\begin{abstract}
The infection of legume plants by rhizobia is tightly regulated to ensure accurate bacterial penetration, infection, and development of functionally efficient nitrogen-fixing root nodules. Rhizobial Nod factors (NF) have key roles in the elicitation of nodulation signaling. Infection of white clover roots also involves the tightly regulated specific breakdown of the noncrystalline apex of cell walls in growing root hairs, which is mediated by Rhizobium leguminosarum bv. trifolii cellulase CelC2. Here, we have analyzed the impact of this endoglucanase on symbiotic signaling in the model legume Medicago truncatula. Ensifer meliloti constitutively expressing celC gene exhibited delayed nodulation and elicited aberrant ineffective nodules, hampering plant growth in the absence of nitrogen. Cotreatment of roots with $\mathrm{NF}$ and $\mathrm{CelC} 2$ altered $\mathrm{Ca}^{2+}$ spiking in root hairs and induction of the early nodulin gene ENOD11. Our data suggest that CelC2 alters early signaling between partners in the rhizobia-legume interaction.
\end{abstract}

Legumes are often used as a rotation crop to naturally enhance the nitrogen content of soils, due to their capacity to establish root-nodule symbioses with $\mathrm{N}$-fixing microorganisms, collectively known as rhizobia. The outcome of this mutualistic association is the formation of root nodules in which rhizobia reduce the inert atmospheric form of nitrogen into compounds easily assimilated by plants. The infection process during the establishment of a rhizobia-legume symbiotic relationship commences with a complex molecular dialogue between the soil bacteria and the plant, followed by a series of steps guided by reciprocal signal exchanges. Nodulation is activated upon bacterial perception of plant flavonoids, which, in turn, induce expression of rhizobial

Marta Robledo and Esther Menéndez made an equal contribution to this work.

Current address for Esther Menéndez: Laboratório de Microbiologia do Solo. ICAAM-Instituto de Ciências Agrárias e Ambientais Mediterrânicas, Universidade de Évora, Portugal.

${ }^{\dagger}$ Corresponding author: Pedro F. Mateos; E-mail: pfmg@usal.es

Funding: This work was supported by Ministerio de Economía y Competitividad grant AGL2015-70510-R.

*The $e$-Xtra logo stands for "electronic extra" and indicates that three supplementary figures are published online.

(C) 2018 The American Phytopathological Society nodulation genes involved in the synthesis and secretion of lipochitooligosaccharide signals called Nod factors (NF). These specific molecules are recognized by specialized plant receptors and elicit several responses in susceptible root-hair cells, such as rhythmic $\mathrm{Ca}^{2+}$ oscillations termed $\mathrm{Ca}^{2+}$ spiking (Oldroyd 2013; Sieberer et al. 2012). $\mathrm{Ca}^{2+}$ spiking is a feature common to both arbuscular mycorrhiza and root nodule symbioses, which can be induced by picomolar concentrations of NF $\left(10^{-11}\right.$ to $\left.10^{-12} \mathrm{M}\right)$ (Shaw and Long 2003). In Medigaco truncatula, nuclear $\mathrm{Ca}^{2+}$ oscillations are mediated by cyclic nucleotide-gated channels located in the nuclear envelope (Charpentier et al. 2016).

These $\mathrm{Ca}^{2+}$ oscillations are part of a signal transduction cascade that triggers root-hair curling and nodule organogenesis (Jones et al. 2007). First, a $\mathrm{Ca}^{2+}$ calmodulin-dependent kinase (CCaMK) integrates the sequential changes in $\mathrm{Ca}^{2+}$ concentration (Lévy et al. 2004; Mitra et al. 2004) and activates the GRAS domaincontaining transcriptional regulators NSP1 and NSP2. These regulators activate transcription of early nodulin genes (ENODs) (Hirsch et al. 2009), involved in bacterial infection or nodule initiation (Gleason et al. 2006; Kaló et al. 2005; Smit et al. 1987).

The dedifferentiation of cortical cells, through reactivation of their mitotic activity, leads to the generation of the nodule primordium (Oldroyd 2013; Oldroyd and Downie 2008). Concomitantly, curled root hairs entrap rhizobia, which penetrate the cell and develop a tubular infection thread that grows through the epidermal root-hair cell into the nodule primordia. Upon release by endocytosis, invading bacteria become enclosed within new intracellular plant organelles called symbiosomes and complete a morphological differentiation process to bacteroids, the nitrogen fixation-competent rhizobial state (Oldroyd et al. 2011).

Despite the benefits for both partners, bacterial entry into host root cells requires not only an appropriate recognition of rhizobial cells to maintain compatibility but, also, a precise balance to preserve the host survival and viability, thus avoiding plant defense responses. A key step of this process is the local plant cellwall degradation required for rhizobia penetration into root hairs, leading to plant-made infection thread formation and further release of bacteria into the cells of nodule primordia. More than 50 different strains capable of forming diazotrophic plant symbiosis have been shown to share cellulase activity (Robledo et al. 2008), and all rhizobial genomes sequenced to date harbor genes encoding glycosyl hydrolase enzymes. Furthermore, genes encoding endoglucanases are widespread and commonly expressed among species of all rhizobial genera (Robledo et al. 2011b).

Our previous studies addressing the role of these hydrolytic enzymes in primary host infection through root-hair tips by 
rhizobia have shown that Rhizobium leguminosarum biovar trifolii ANU843 produces two cell-bound cellulases, designated CelC1 and CelC2 (Mateos et al. 1992). However, only CelC2 can completely erode the root hair of the compatible ANU843 legume host, white clover (Trifolium repens) (Mateos et al. 2001). This highly localized noncrystalline tip erosion of white clover host root-hair cell walls is far different from the extensive degradation of root hairs upon treatment with commercial fungal cellulases and was not evident when the purified enzyme was incubated with seedling roots of the nonhost legume alfalfa (Medicago sativa) (Robledo et al. 2008). Furthermore, CelC2mediated white clover root-hair tip cell-wall erosion leads to a localized hole formation, whose size, geometry, and location match the entry point of the bacteria during primary infection of white clover (Mateos et al. 2001). CelC2 is a 1,4- $\beta$-D-endoglucanase belonging to glycosyl hydrolase family 8 and exhibits high substrate specificity for noncrystalline cellulose. ANU843 celC null mutants were unable to canonically invade its clover host through root hairs (Robledo et al. 2008), confirming its essential role in primary infection required for development of the root nodule symbiosis. We have also shown the role of Rhizobium CelC2 enzyme in cellulose biosynthesis concomitant to adhesion to the plant cell and biofilm formation (Robledo et al. 2012).

On the other hand, microscopy analysis of an ANU843 derivative strain constitutively overexpressing the celC gene in clover revealed an exaggerated tip degradation of host root hairs and extensive hydrolysis of the noncrystalline zone of the infection thread cell wall during secondary infection, i.e., at the point of bacterial release into plant cells. Besides this observation, the CelC2-overproducing strain induces lower number of nodules, and signs of reactive oxygen species production in root tissues were more evident when compared with wild-type infection (Robledo et al. 2011), suggesting that CelC2 triggers plant defense responses. These data indicate that endoglucanase production must be tightly controlled to prevent an ineffective nitrogen-fixing root nodule symbiosis.

All these results support a key symbiotic role of this cell-bound enzyme, but whether these endoglucanases influence legumerhizobia signaling during symbiosis remains unknown. In this work, we have compared the infection and nodulation responses of the model legume Medicago truncatula to inoculation with the Ensifer meliloti 1021 wild-type strain, which lacks a celC gene homolog in its genome, or with a derivative strain constitutively expressing the $R$. leguminosarum celC gene $\left(1021 \mathrm{C}^{+}\right)$. Plants inoculated with $1021 \mathrm{C}^{+}$showed a severe delay in growth and in the appearance of nodules, which were aberrant and much less efficient for nitrogen fixation in comparison with wild-type nodules. These aberrant phenotypes are accompanied by a significant alteration in $\mathrm{Ca}^{2+}$ spiking and ENOD11 induction. These results show that both heterologous expression and exogenous addition of the cellulase can interfere with symbiotic signaling.

\section{RESULTS}

\section{Heterologous expression of the celC gene in Ensifer meliloti 1021.}

To further analyze the symbiotic role of $R$. leguminosarum bv. trifolii CelC2 endoglucanase, E. meliloti 1021 was transformed with a midcopy plasmid (30 to 40 copies per cell) constitutively expressing celC gene. The 1021 reference strain has no recognizable celC homolog or ortholog (Galibert et al. 2001), but a gene encoding an endoglucanase belonging to glycosyl hydrolase family 26 has been identified in this genome (Robledo et al. 2008). Nevertheless, other rhizobial members recently reclassified into genus Ensifer, i.e., E. medicae WSM419, E. meliloti GR4, and several E. fredii strains (HH103, NGR234, and USDA237), harbor celC orthologs located in symbiotic plasmids (Reeve et al. 2010; Weidner et al. 2012).

The wild-type E. meliloti 1021 strain and its $\mathrm{CelC}_{2}^{+}$derivative were compared for their ability to hydrolyze carboxymethylcellulose (CMC) using a previously described double-layer plate assay (Mateos et al. 1992), which reliably detects endoglucanase activity. Under these conditions $\left(\mathrm{pH} 5,37^{\circ} \mathrm{C}\right)$, no E. meliloti $1021-$ derived CMC hydrolysis was evident on plates (Fig. 1A). In contrast, E. meliloti $1021 \mathrm{C} 2^{+}$cultures or sonicated cell extracts evidenced carboxymethylcellulase (CMCase) activity (Fig. 1A). Using $1021 \mathrm{C}^{+}$culture supernatants as the source of enzymes, no CMC activity was detected (data not shown), confirming that the protein remains cell-bound, as in wild-type R. leguminosarum bv. trifolii.
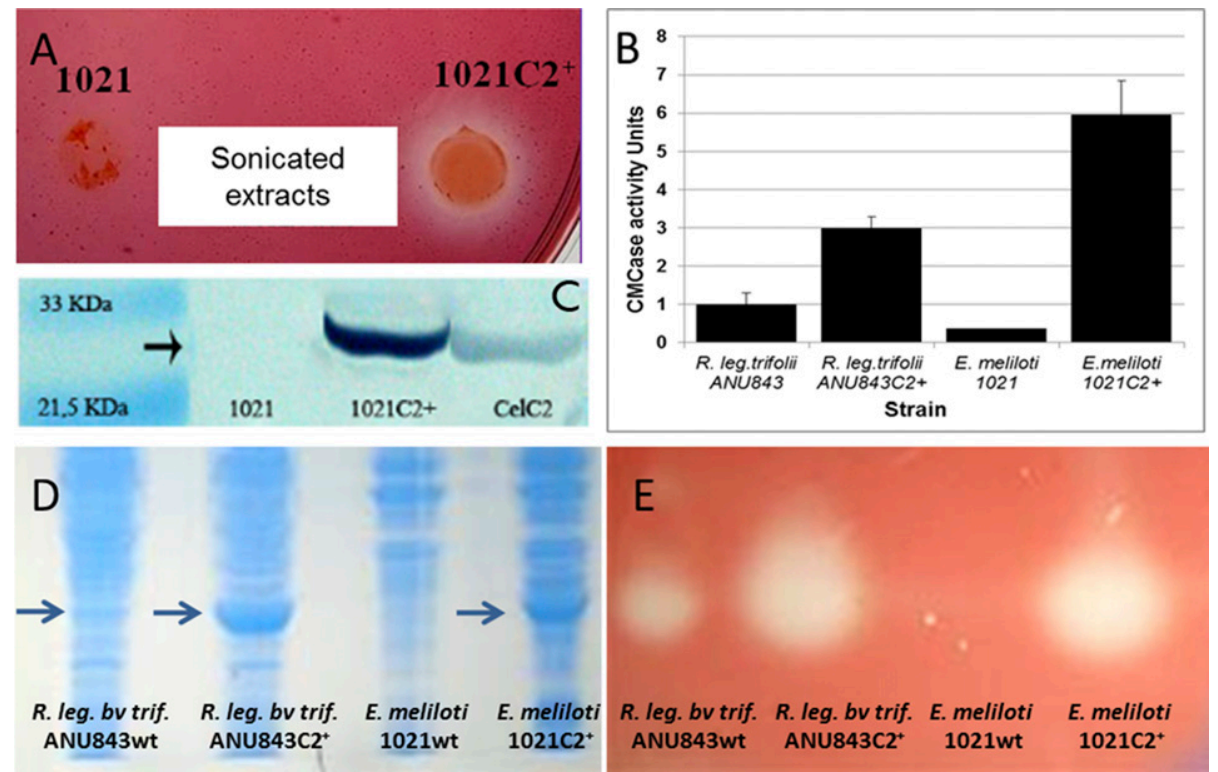

Fig. 1. Carboxymethylcellulase activity of Rhizobium leguminosarum bv. trifolii and Ensifer meliloti strains detected by A, double-layer plate assay, B, quantitative enzyme 2,2-bicinchoninic acid assay, C, Western blot, D, sodium dodecyl sulfate polyacrylamide gel electrophoresis (the arrows point to the CelC2 enzyme), and $\mathbf{E}$, activity stain overlay. All the cell extracts were obtained from equivalent cell numbers and were adjusted to contain equal amounts of total protein. Purified CelC2 enzyme was used as positive control in D. 
As shown before, quantitative 2,2-bicinchoninic acid (BCA) assays with whole-cell extracts barely detected CMCase activity in the 1021 wild-type strain (Jiménez-Zurdo et al. 1996). However, this assay revealed a sixfold increase of the total CMCase activity in $1021 \mathrm{C} 2^{+}$as compared with $R$. leguminosarum bv. trifolii ANU843 parental strain and a twofold increase in comparison with the ANU843C $2^{+}$overproducing derivative strain (Fig. 1B) (Robledo et al. 2011). An immunoblotting assay further confirmed absence of CelC2 in total protein extracts of E. meliloti 1021 and the competence of $1021 \mathrm{C}^{+}$derivative strain to synthesize the protein (Fig. 1C).

Separation of the sonicated cell extracts by sodium dodecyl sulfate-polyacrylamide gel electrophoresis (SDS-PAGE) (Fig. 1D) and the activity assay of the proteins resolved in the gels (Fig. 1E) also demonstrated that $1021 \mathrm{C}^{+}$strain produces an enzyme that matches the size of $R$. leguminosarum bv. trifolii ANU843 CelC2 enzyme (31 KDa) as well as presents CMCase activity. All these assays confirmed that cellulase CelC2 is expressed, processed, and localized in the $1021 \mathrm{C}^{+}$strain as in R. leguminosarum bv. trifolii ANU843.

\section{E. meliloti $1021 \mathrm{C2}^{+}$displays}

an aberrant symbiotic phenotype with $M$. truncatula.

Greenhouse assays were conducted to test the symbiotic performance of E. meliloti 1021 and its derivative strain $1021 C 2^{+}$on
M. truncatula A17 plants grown under nitrogen-limited conditions (Figs. 2 and 3). Plants inoculated with the wild-type strain showed a proper development; however, the $1021 \mathrm{C}^{+}$-inoculated plants had similar appearance to mock-treated plants (Fig. 2A). Statistical analysis of shoot length, dry weight, and nitrogen content per plant confirmed significant differences between 1021 and the cellulase-overproducing derivative strain (Fig. 2B to D), suggesting a reduction in nitrogen fixation ability of $1021 \mathrm{C}^{+}$.

Both strains were able to induce nodules in M. truncatula roots. Those elicited by the wild-type strain were typical indeterminate nodules (Fig. 3A); however, most plants inoculated with $1021 \mathrm{C}^{+}$developed smaller nodules, mostly with an aberrant morphology (Fig. 3D). Histological cross-sections of $1021 \mathrm{C}^{+}$nodules showed disorganized cellular structures (Fig. $3 \mathrm{E}$ and $\mathrm{F}$ ) that differ from those containing nitrogen-fixing symbiosomes observed in the wild-type nodules (Fig. 3B and C). Plant nodulation kinetics during in vitro axenic assays also revealed a significant delay in nodule formation by the $1021 \mathrm{C} 2^{+}$ derivative with respect to the wild-type strain, as assessed by recording the mean number of nodules per plant at different timepoints after inoculation (Fig. 3G).

Taken together, $M$. truncatula plants inoculated with the E. meliloti 1021 derivative heterologously expressing CelC2 exhibit nodulation and growth defects that are similar to those observed in $T$. repens inoculated with $R$. leguminosarum bv. trifolii
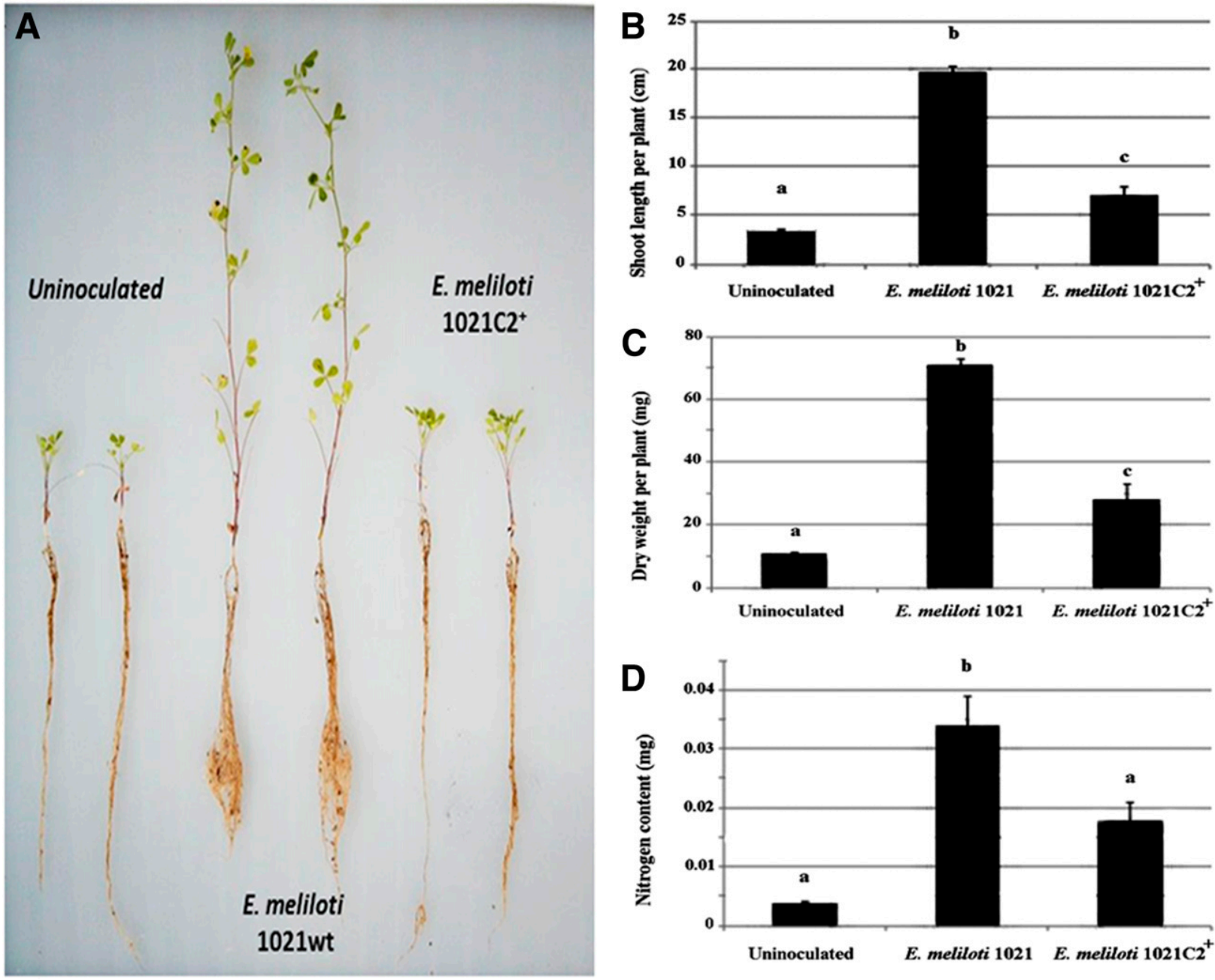

Fig. 2. A, Whole-plant phenotypes of Medicago truncatula inoculated with Ensifer meliloti 1021 (center), the CelC2 overproducing derivative strain (right) and uninoculated (left). B, Shoot length, $\mathbf{C}$, dry weight, and D, nitrogen content per plant at the end of the assay. Data are the mean of at least 30 replicates per treatment. Three biological repetitions are represented. Error bars represent standard error. Values followed by the same letter are not significantly different from each other at $P<0.01$, according to Fisher's protected least-significant differences test statistic. 
overexpressing CelC2 (Robledo et al. 2011), which also led to retardation of nodulation in clover (unpublished data). In both cases, uncontrolled bacterial invasion of the nodule cells leads to defects in symbiosome formation and, therefore, to infective nonfixing nodules.

\section{CelC2 cellulase affects $\mathrm{Ca}^{2+}$ spiking} in $M$. truncatula root hairs.

To determine whether the delay in nodule formation by the $\mathrm{CelC}^{+}$derivative strains resulted from decreased sensitivity to $\mathrm{NF}$, we assessed the effect of purified CelC2 cellulase on NFinduced $\mathrm{Ca}^{2+}$ spiking responses. Cellulase CelC2 was purified from $R$. leguminosarum bv. trifolii ANU843C2 $2^{+}$as described before (Robledo et al. 2008). Elution fractions were separated by SDS-PAGE and were stained with silver to confirm enzyme purity (Supplementary Fig. S1). Cellulase activity of the selected fraction was also assessed by Congo red staining, using a commercial cellulase as control.

Distribution of spiking signatures in root hairs of $M$. truncatula plants expressing the YC2.1 cameleon $\mathrm{Ca}^{2+}$ reporter (Miwa et al. 2006) showed that $\mathrm{Ca}^{2+}$ spiking was totally abolished by a concentration of $5 \mathrm{pg} / \mu \mathrm{l}(1 \mathrm{U})$ of purified CelC2 in $43 \%$ of
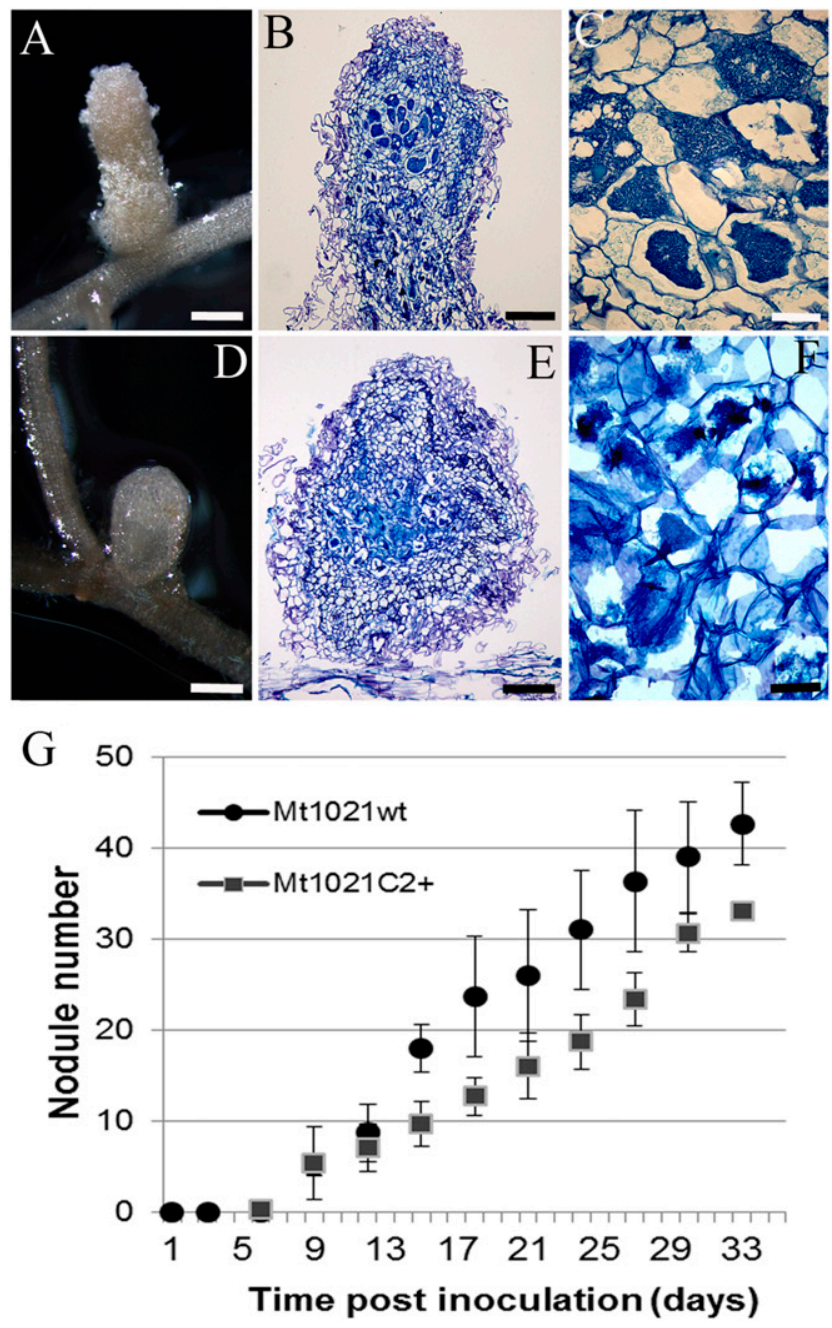

Fig. 3. Medicago truncatula nodule development 33 days postinoculation with $\mathbf{A}$ to $\mathbf{C}$, Ensifer meliloti 1021 or $\mathbf{D}$ to $\mathbf{F}$, the $\mathrm{CelC} 2^{+}$derivative strain. B, $\mathrm{C}, \mathrm{E}$, and $\mathrm{F}$ show nodule sections stained with toluidine blue. Bars $=1 \mathrm{~mm}$ (A, D), $200 \mu \mathrm{m}$ (E), $100 \mu \mathrm{m}$ (B), and $16 \mu \mathrm{m}$ (C, F). G, Time course of E. meliloti versus the $\mathrm{CelC} 2^{+}$derivative strain-induced nodule production in $M$. truncatula. Three biological repetitions are represented. Error bars indicate standard error. analyzed root hairs (Fig. 4A). In $40 \%$, the signature was strongly affected and only $17 \%$ of the CelC2-treated root hairs showed wild-type $\mathrm{Ca}^{2+}$ spiking. There were no signs of root hair-tip degradation, i.e., hole on tip phenotype production, during the time course of the $\mathrm{Ca}^{2+}$-spiking assays (Fig. 4B).

To check whether other components of the CelC2 cellulase elution fraction could affect spiking, the enzyme preparation was heated, and the absence of endoglucanase activity was confirmed. Addition of heat-inactivated cellulase CelC2 did not abolished $\mathrm{Ca}^{2+}$ spiking in any of the analyzed root hairs (Supplementary Fig. S2).

\section{CelC2 cellulase cannot degrade NF signal molecules.}

Given that $\mathrm{CelC} 2$ cellulase rapidly affects $\mathrm{Ca}^{2+}$ spiking, we wondered whether this enzyme could mediate degradation of bacterial signal molecules involved in recognition between the symbiotic partners. NF molecules share an acylated chitin oligomeric backbone with various substitutions at certain residues involved in plant host specificity. This chitooligosaccharide backbone consists of 4-5 $\beta$-1,4-linked glucosamine residues, which, despite being different from those in the natural CelC2 substrate (1,4- $\beta$-D-glucan), could be susceptible to CelC2-catalyzed hydrolysis.

Therefore, enzymatic reactions with purified CelC2 and E. meliloti NF were perfomed. Reactions contained $1 \mu \mathrm{M}$ of nondegraded NF and $0.5 \mu \mathrm{g}$ of active or heat-inactivated CelC2 enzyme per microliter $(100 \mathrm{U})$ and were performed at $40^{\circ} \mathrm{C}$ and $\mathrm{pH} 5$, the optimal conditions for cellulase CelC2 activity (Mateos et al. 2001). Samples before and $5 \mathrm{~h}$ after incubation were subsequently subjected to high-pressure liquid chromatography

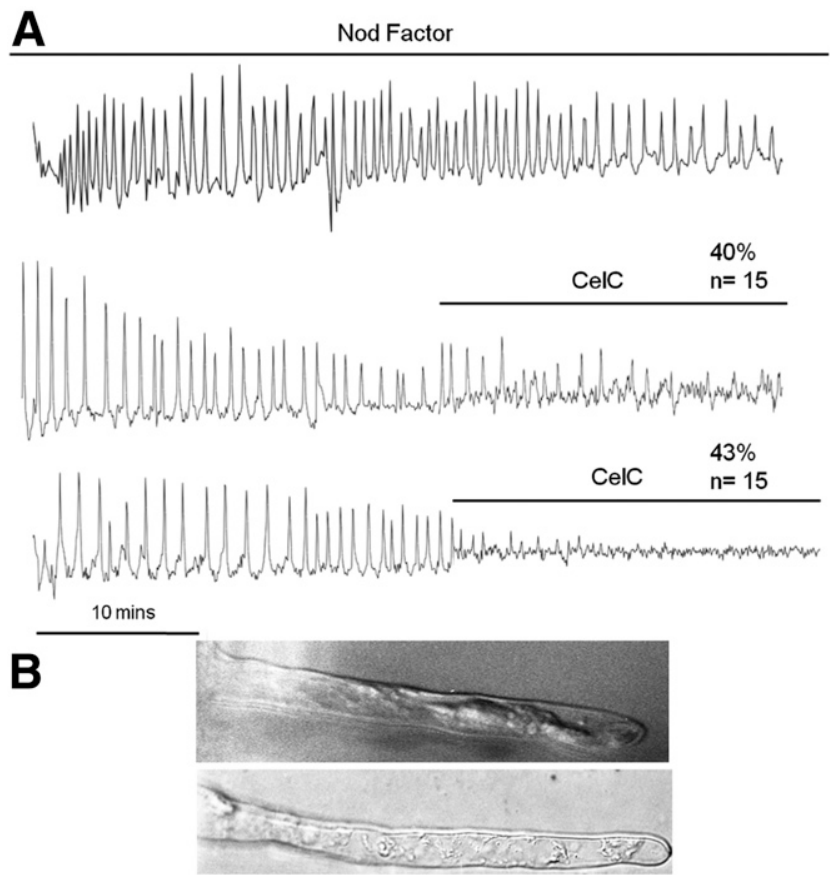

Fig. 4. CelC2 effect on Nod factor (NF)-induced $\mathrm{Ca}^{2+}$ spiking. A, Representative $\mathrm{Ca}^{2+}$ traces of Medicago truncatula root-hair cells preinduced with $10 \mathrm{pM} \mathrm{NF}$ and secondarily treated with $5 \mathrm{pg} \mathrm{CelC} 2$ per liter $(1 \mathrm{U})$. The $y$ axes represent de-trended cyan fluorescent protein-yellow fluorescent protein (CFP:YFP) ratios in arbitrary units. The top trace is a reference, showing NF-induced $\mathrm{Ca}^{2+}$ spiking in roots. The percentage of visualized cells that follow each behavior and the number of cells tested is shown. $\mathbf{B}$, Lower image, representative differential interference contrast (DIC) image of a $M$. truncatula intact root hair after treatment with $5 \mathrm{pg}$ of $\mathrm{CelC} 2$ per microliter (1 U). Upper image, representative DIC image of a M. truncatula intact root hair with no treatment. $\mathrm{Ca}^{2+}$ measurements were generated from cameleon-transformed plants (Miwa et al. 2006). 
(HPLC) mass spectrometry. This analysis revealed the lack of NF cleavage subproducts in all reactions (Supplementary Fig. S3). We cannot, therefore, explain the CelC2-mediated $\mathrm{Ca}^{2+}$ spiking defects by direct cleavage of NF signal molecules.

\section{NF-mediated plant early nodulin expression} is reduced in the presence of heterologously expressed cellulase CelC2.

$\mathrm{Ca}^{2+}$ spiking is associated with the induction of many early nodulation genes such as ENOD11 (Gleason et al. 2006; Kaló et al. 2005; Smit et al. 1987). To assess the effects of CelC2 cellulase on NF-induced gene expression, we used $M$. truncatula plants stably transformed with $\beta$-glucuronidase (GUS) regulated by the ENOD11 promoter (Journet et al. 2001). Three days after germination, plants were treated with either the E. meliloti wildtype strain or its $1021 \mathrm{C}^{+}$derivative. In parallel, the effect of the addition of purified NF in the presence or in the absence of purified CelC2 enzyme was also tested. GUS activity was determined both by plant root staining and fluorimetric quantification at different timepoints after treatments.

Control untreated plants showed no GUS activity in epidermal root cells after GUS staining. We found typical Nod-dependent ENOD11 promoter activation in a zone of epidermal cells, starting approximately $0.6 \mathrm{~cm}$ from the root tip, in plants treated with either the wild-type strain or the purified NF (Fig. 5A and
C). Interestingly, inoculation with $E$. meliloti $1021 \mathrm{C} 2^{+}$reduced induction of ENOD11, especially $24 \mathrm{~h}$ after treatment (Fig. 5A). Fluorimetric quantification of GUS in roots $24 \mathrm{~h}$ after inoculation with $1021 \mathrm{C}^{+}$showed slightly lower levels of ENOD11 induction than after addition of wild-type strain (Fig. 5B). Further, cotreatment with $5 \mathrm{pg}$ of CelC2 per microliter $(1 \mathrm{U})$ almost abolished NF induction of ENOD11, as revealed by both histochemical localization and quantification of activity (Fig. 5C and D). These results are in correlation with the $\mathrm{Ca}^{2+}$ signaling observations, indicating that $\mathrm{CelC} 2$ could repress early nodulin gene expression induced by rhizobial NF.

\section{DISCUSSION}

Rhizobia must breach plant cell walls to colonize intact inner plant tissues. The cellulolytic activity of the rhizobial CelC2 enzyme leads to a localized erosion of root-hair tips at the areas in which infection threads develop (Robledo et al. 2011). This suggests that bacterial enzymes may contribute to the breakdown of the plant cell wall. Subsequent growth of infection threads across adjacent root cells would probably require the sequential action of plant enzymes degrading other components of the cell wall, i.e., pectate lyases, as has been recently reported in Lotus japonicus (Xie et al. 2012). In M. sativa and M. truncatula, plant polygalacturonases induced upon rhizobia
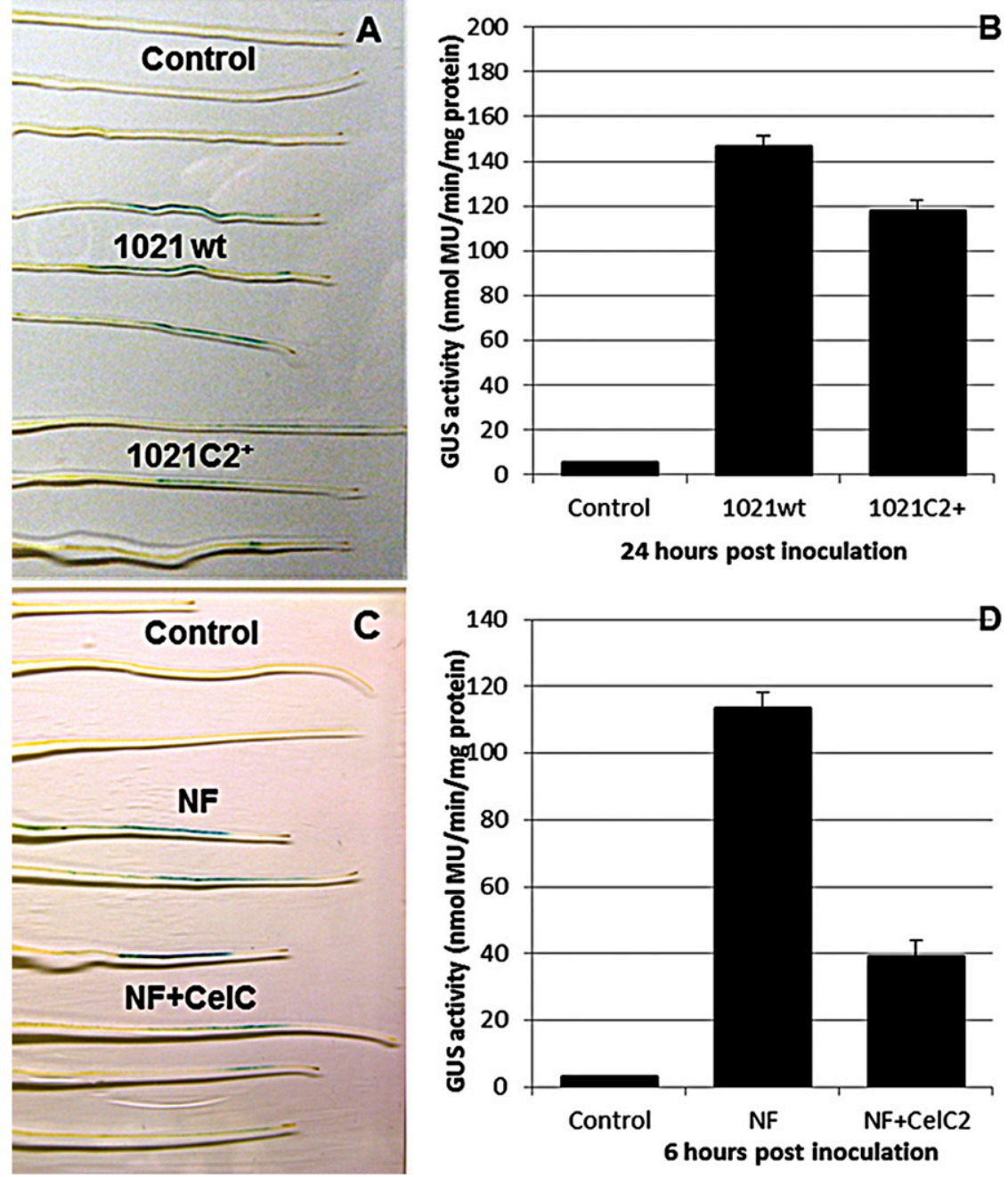

Fig. 5. Histochemical localization and quantification of $\beta$-glucuronidase (GUS) activity induced in roots of Medicago truncatula transgenic plants carrying a promoter fusion of MtENOD11 to GUS reporter gene either $\mathbf{A}$ and $\mathbf{B}, 24 \mathrm{~h}$ postinoculation with Ensifer meliloti 1021 and $1021 \mathrm{C} 2^{+}$strains or $\mathbf{C}$ and $\mathbf{D}$, after treatment with $1 \mathrm{pM}$ Nod factor (NF) with and without $1 \mathrm{U}$ purified CelC2. 
inoculation may be responsible for these subsequent steps (Muñoz et al. 1998; Rodríguez-Llorente et al. 2003). However, it remains to be elucidated if all rhizobia-legume symbioses share the same infection mechanisms.

CelC2 homologs have been identified in all studied species of the genus Rhizobium (Robledo et al. 2011b) and there are ortholog enzymes in other genera, such as genera Ensifer, Agrobacterium, and Burkholderia (Reeve et al. 2010; Weidner et al. 2012). However, in silico analyses of the E. meliloti 1021 genome revealed the absence of cellulase CelC2 ortholog sequences, suggesting that this enzyme does not participate in all MedicagoEnsifer symbiosis. This analysis agrees with previously published results that indicate the absence of root hair-tip erosion on CelC2-treated M. sativa seedlings (Robledo et al. 2008). Mechanisms of rhizobial colonization may, therefore, differ between plant-rhizobial partners, particularly regarding mechanisms underpinning cell-wall degradation.

In this work, we have studied the effect of the heterologous expression of CelC2 in the symbiosis of E. meliloti with its compatible legume host, $M$. truncatula. Overproduction of CelC2 in E. meliloti 1021 impairs the symbiosis with $M$. truncatula plants leading to nodulation retard and aberrant nodule formation. This resembles the symbiotic defect during the $T$. repens-ANU843C2 ${ }^{+}$ symbiosis (Robledo et al. 2011). Formation of aberrant nodules is linked to extensive degradation of the noncrystalline cellulose at the points of bacteria release from infection threads. However, the absence of genetic tools to study NF signaling in Trifolium plants hampered further research on this host plant.

The model legume $M$. truncatula also showed delayed nodulation kinetics upon inoculation with the CelC2 overexpressing strain $1021 \mathrm{C}^{+}$, anticipating common strain-independent responses to rhizobial cellulases in both plants. CelC2 interference with early NF perception could therefore explain this symbiotic phenotype. These data agree with those reported previously, showing that cell wall-degrading enzymes interfere with NF signaling in M. sativa root hairs (Carden and Felle 2003). It is, therefore, tempting to speculate that cellulases may influence the mechanisms of NF-induced $\mathrm{Ca}^{2+}$ spiking in both host and nonhost plant legumes.

NFs are rapidly degraded in the host rhizosphere, mainly by plant chitinases. Interestingly, E. meliloti lipo-chitooligosaccharides are not cleaved by chitinases but by a legume-synthesized hydrolase called MtNFH1, which is structurally related to enzymes belonging to glycoside hydrolase family 18 (Tian et al. 2013). In this study, we showed that even if NFs share a similar structure to the natural substrate of cellulase CelC2, this enzyme does not cleave E. meliloti signal molecules in vitro. This result is consistent with previously published studies showing that CelC2 cellulase cannot degrade the $\beta-1,4$ heptaglucose backbone in the repeated octasaccharide of E. meliloti succinoglycan (Robledo et al. 2008) and reinforces the CelC2 cellulase substrate specificity. Although the CelC2 effect on NF may differ in vivo, these results suggest that $\mathrm{CelC} 2$ activity on the plant cell walls rather than CelC2-mediated NF cleavage is responsible for the observed defects in $\mathrm{Ca}^{2+}$ spiking and early nodulin induction upon cellulase treatment. It could then be hypothesized that $\mathrm{Ca}^{2+}$ spiking inhibition is the consequence of the elicitation of plant defense responses by oligomers derived from CelC2mediated plant cell wall hydrolysis, as previously reported in the ANU843C $2^{+}-T$. repens symbiosis (Robledo et al. 2011). It is also plausible that CelC2 directly impacts symbiosis signaling through an effect on NF membrane-bound receptors, which have an extracellular domain.

An interesting hypothesis is that the action of CelC2 during infection may be the transient suppression of NF-mediated signaling. Whether such suppression is relevant during a canonical rhizobial primary or secondary infection, or both, remains unknown. Taken together, our data suggest that endoglucanases participate not only in colonization and infection of legume roots but can also interfere in symbiosis signaling, which may be an important negative feedback during the symbiotic process.

\section{MATERIALS AND METHODS}

\section{Bacterial strains and DNA methods.}

Wild-type strain Ensifer meliloti 1021 and its derivative strain $1021 \mathrm{C}^{+}$(this work) were routinely grown in tryptone yeast or yeast mannitol agar medium (Somasegaran and Hoben $1994)$ at $28^{\circ} \mathrm{C}$. Escherichia coli DH5 $\alpha$, used for cloning and maintenance of plasmid constructs, was grown in Luria Bertani broth at $37^{\circ} \mathrm{C}$. Kanamycin was added to the media, when required, at the following concentrations: $50 \mu \mathrm{g} / \mathrm{ml}$ for Escherichia coli and $R$. leguminosarum bv. trifolii and $200 \mu \mathrm{g} / \mathrm{ml}$ for E. medicae. Plasmid DNA preparation and recombinant DNA techniques were performed according to standard procedures (Sambrook et al. 1989). To generate the recombinant $1021 \mathrm{C} 2^{+}$, plasmid pJZC2 (Robledo et al. 2011) was mobilized into E. meliloti 1021 by a triparental mating, using pRK2013 as helper. Transformants were checked by polymerase chain reaction, using primers CelCexF and C2R (Robledo et al. 2008) to confirm the presence of the transgene of interest.

\section{Plant material and growth conditions.}

Medicago truncatula seeds of cv. Jemalong line A17 were used as the wild type of the L416 line, which was transformed with pMtENOD11-GUS (Charron et al. 2004) and of the YC2.1 line, transformed with the yellow cameleon YC2.1 on p35Syc2.1-kan (Miwa et al. 2006). Seeds were scarified with sand paper, were surface-sterilized in $100 \%$ bleach, were imbibed in sterile water for $5 \mathrm{~h}$, and were plated on $1 \%$ deionized water agar plates. Seeds were incubated for 24 to $48 \mathrm{~h}$ at $4{ }^{\circ} \mathrm{C}$ and were germinated on inverted agar plates at room temperature for $30 \mathrm{~h}$. For short-term assays, seedlings with straight roots were then transferred to Fähraeus medium (Fähraeus 1957) supplemented with $0.1 \mathrm{mM}$ 2-aminoethoxyvinyl-glycine (Sigma-Aldrich) and solidified with $1 \%$ agar, were inoculated with $1 \mathrm{ml}$ of a bacterial suspension (optical density at $600 \mathrm{~nm}\left[\mathrm{OD}_{600}\right]=0.5 ; 4 \times 10^{8}$ bacterial cells) in nitrogen-free Fähraeus medium, and were placed in a $24^{\circ} \mathrm{C}$ growth chamber with a photoperiod of $16 \mathrm{~h}$ of light, $8 \mathrm{~h}$ of dark and a light intensity of 60 photons per $\mathrm{m}^{2} \mathrm{~s}^{-1}$. The bottom half of the plates was covered with foil to shade the roots until they were used for the different assays. For nodulation assays, surface-disinfected seedlings were transferred to tubes containing $\mathrm{N}$-free Fähraeus liquid medium and were inoculated as described above. Nodule number was recorded every 2 to 3 days. Representative nodules from each treatment were excised and were kept on $4 \%$ p-formaldehyde for histological studies as described (Robledo et al. 2011). For greenhouse assays, surfacedisinfected seedlings were transferred to pots containing sterile vermiculite as support and, $48 \mathrm{~h}$ after, each plant was inoculated. Pots were watered as needed and were fertilized once every week with nitrogen-free Fähraeus nutrient solution. Plants were harvested 3 months after inoculation to determine shoot length and dry weight. The nitrogen content was determined by an elemental analyzer (Leco Truspec CN) at the Ionomic Service of Centro de Edafología y Biología Aplicada del Segura (CEBAS-CSIC). Data were analyzed by one-way analysis of variance, with the mean values compared using Fisher's protected least-significant differences $(P=0.01)$.

\section{Enzyme assays.}

Cellulase activity in sonicated bacterial cultures standardized to cell density was examined by double-layer plate enzyme assay 
using Congo red staining, reducing sugar assay using BCA, and SDS-PAGE followed by activity stain overlay, as described before (Jiménez-Zurdo et al. 1996; Mateos et al. 1992). One unit of enzyme activity ( $1 \mathrm{U})$ is defined as the amount releasing $1 \mathrm{nmol}$ of reducing sugar equivalent per minute at $40^{\circ} \mathrm{C}$. CelC 2 purification and quantification was performed as described before (Robledo et al. 2008). When necessary, CelC2 cellulase was catalytically inactivated after $2 \mathrm{~min}$ of incubation at $100^{\circ} \mathrm{C}$.

Inmunoblotting assays were performed with a polyclonal antibody against rhizobial CelC2 protein. Equal amounts of E. meliloti 1021 and $1021 \mathrm{C}^{+}$protein extracts were separated on a $12 \%$ polyacrylamide gel and were then transferred to a nitrocellulose membrane (Bio-Rad), according to manufacture's instructions. Membrane was blocked in blocking solution $(1 \%$ low-fat milk Tris-buffered saline [TBS] buffer) for $30 \mathrm{~min}$ and was then incubated overnight in a 1:3 blocking solution containing 1:10 anti-CelC2 antisera (Inmunostep S.L.). Membrane was rinsed for $5 \mathrm{~min}$ three times in TBS-Tween $200.05 \%$ solution and was then incubated for $1 \mathrm{~h}$ with a 1:500 dilution of antirabbit immunoglobulin G-peroxidase antibody (Sigma-Aldrich). The membrane was washed with TBS and was visualized with peroxidase substrates (4-chloro-1-naphthol; Sigma-Aldrich) in a color development.

To check NF integrity, purified CelC 2 enzyme at $0.5 \mu \mathrm{g} / \mu \mathrm{l}$ $(100 \mathrm{U})$ and $1 \mu \mathrm{M} \mathrm{E}$. meliloti NF and active or heat-inactivated CelC2 enzyme were combined and incubated in phosphatecitric acid buffer (pH 5.0) at $40^{\circ} \mathrm{C}$. Each of the enzymatic reactions $(10 \mu \mathrm{l})$ were analyzed by reverse-phase HPLC, through an XBRIGDE column $(\mathrm{C} 18,100 \times 2.1 \mathrm{~mm}, 3.5 \mu \mathrm{m}$; Waters $)$, which is coupled to a mass spectrometer (Agilent 1100 Series LC/MSD Trap XCT Ultra ion trap mass spectrometer; Agilent Technologies), in a protocol similar to that previously reported (Tian et al. 2013).

\section{$\mathrm{Ca}^{2+}$ spiking analysis.}

$\mathrm{Ca}^{2+}$ spiking changes in root hairs of $M$. truncatula YC2.1 lines expressing the $\mathrm{Ca}^{2+}$ reporter yellow cameleon 2.1 (Miwa et al. 2006) were tested 1 to 2 days after germination. Seedlings were mounted on slides and NFs were added to a final concentration of $10 \mathrm{pM}$, as a positive control for the ability of root hairs to initiate $\mathrm{Ca}^{2+}$ spiking. Root hairs were imaged for a minimum of $30 \mathrm{~min}$ after addition of either buffer or a solution containing CelC at $5 \mathrm{pg} / \mu \mathrm{l}(1 \mathrm{U})$ to determine whether $\mathrm{Ca}^{2+}$ spiking was triggered. Treatments were added to the edge of the liquid in the incubation chamber and were allowed to diffuse to the root to avoid disturbing root hairs. A control treatment using heat-denaturalized $\mathrm{CelC}$ enzyme $\left(100^{\circ} \mathrm{C}, 2 \mathrm{~min}\right)$ was also included.

Analyses of changes in fluorescence due to changes in $\mathrm{Ca}^{2+}$ were done using epifluorescence microscopy as described (Wais et al. 2002), using a Nikon TE2000U inverted microscope (Nikon Instruments Inc.) coupled to a Hamamatsu Photonics digital charge device camera (Hamamatsu Photonics UK Ltd.). The cyan fluorescent protein (CFP) component of the cameleon was excited at a wavelength of $437 \mathrm{~nm}$ with an 11-nm bandpass using an Optoscan Monochrometer (Cairn Research). Emitted fluorescence was separated by an image splitter with a dichroic mirror and was then passed through an emission filter of $485 \mathrm{~nm}$ for CFP fluorescence and $535(15 \mathrm{~nm})$ (Cairn Research) for the yellow fluorescent protein (YFP) fluorescence. Images were acquired every $5 \mathrm{~s}$ with a 200- to 900-ms exposure time and were analyzed using MetaFluor software (Universal Imaging Corp.).

Regions of interest were outlined on the image and the average pixel intensity was averaged for each image in the data set. The ratio changes were calculated, by dividing YFP intensities using CFP intensities, by exporting the values into Microsoft Excel, converting them to a ratio, and plotting them against time, as described (Capoen et al. 2009). Briefly, to make the time series stationary and enhance spike detection we detrended the YFP/CFP ratio by subtracting a moving average. The number of points used to calculate the moving average for every trace is 25 . Outliers in the traces were removed and were replaced with linear interpolation.

\section{Assessment of ENOD11-GUS expression.}

GUS staining and activity measurement were performed as described (Ding et al. 2008). M. truncatula line 416K plants carrying the ENOD11 promoter driving the expression of GUS were grown on Fähraeus medium for 3 days. Plants were inoculated with $100 \mu \mathrm{l}$ of a suspension of E. meliloti 1021 or $1021 \mathrm{C}^{+}\left(\mathrm{OD}_{600}=0.5\right)$ or $1 \mathrm{pM} \mathrm{NF}$, with or without $0.5 \mathrm{ng} \mathrm{CelC} 2$ protein $(1 \mathrm{U})$ at different timepoints, and all treatments were left until the final timepoint. GUS staining was performed for $2 \mathrm{~h}$ at $37^{\circ} \mathrm{C}$ with $1 \mathrm{mM}$ 5-bromo-4-chloro-3-indolyl- $\beta$-glucuronic acid, $5 \mathrm{mM}$ EDTA, $20 \%$ methanol, and $0.1 \mathrm{M}$ potassium phosphate, $\mathrm{pH}$ 7.0. Subsequently, roots were observed under a stereomicroscope.

The experiments were repeated three times $(n=18)$ with similar results. GUS activity was measured by the fluorimetric assay as described (Jefferson et al. 1987). Six plant roots were ground in liquid nitrogen and were homogenized in GUS extraction buffer $(50 \mathrm{mM}$ sodium phosphate buffer, $\mathrm{pH} 7.5$, $10 \mathrm{mM}$ 2-mercaptoethanol, $10 \mathrm{mM}$ EDTA, 0.1\% Triton X100, and $0.1 \%$ sodium lauryl-sarcosine) for total protein extraction. Enzymatic reactions were performed for $1 \mathrm{~h}$ at $37^{\circ} \mathrm{C}$ in GUS extraction buffer, using $1 \mu \mathrm{g}$ of total protein extract with $1 \mathrm{mM}$ 4-methylumbelliferyl- $\beta$-D-glucuronide as substrate (SigmaAldrich) and were terminated with $1 \mathrm{M} \mathrm{Na}_{2} \mathrm{CO}_{3}$. GUS activities were measured using a microtiter fluorimeter (FL600, Bio-Tek). Standard curves were prepared with a range of increasing concentrations of 4-methylumbelliferone (Sigma-Aldrich).

\section{ACKNOWLEDGMENTS}

We thank W. Capoen and S. Shailes for his help with the $\mathrm{Ca}^{2+}$ spiking analysis and Y. Ding for her contribution with the assessment of ENOD11GUS expression. We are grateful to A. Becker for kindly providing purified E. meliloti 1021 Nod Factors and M. McIntosh for helpful manuscript review. M. Robledo and E. Menéndez were supported by Ph.D. fellowships from the Spanish government.

\section{LITERATURE CITED}

Capoen, W., Den Herder, J., Sun, J., Verplancke, C., De Keyser, A., De Rycke, R., Goormachtig, S., Oldroyd, G., and Holsters, M. 2009. Calcium spiking patterns and the role of the calcium/calmodulindependent kinase CCaMK in lateral root base nodulation of Sesbania rostrata. Plant Cell 21:1526-1540.

Carden, D. E., and Felle, H. H. 2003. The mode of action of cell wall-degrading enzymes and their interference with Nod factor signalling in Medicago sativa root hairs. Planta 216:993-1002.

Charpentier, M., Sun, J., Vaz Martins, T., Radhakrishnan, G. V., Findlay, K., Soumpourou, E., Thouin, J., Véry, A. A., Sanders, D., Morris, R. J., and Oldroyd, G. E. 2016. Nuclear-localized cyclic nucleotide-gated channels mediate symbiotic calcium oscillations. Science 352:1102-1105.

Charron, D., Pingret, J. L., Chabaud, M., Journet, E. P., and Barker, D. G. 2004. Pharmacological evidence that multiple phospholipid signaling pathways link Rhizobium nodulation factor perception in Medicago truncatula root hairs to intracellular responses, including $\mathrm{Ca}^{2+}$ spiking and specific ENOD gene expression. Plant Physiol. 136:3582-3593.

Ding, Y., Kalo, P., Yendrek, C., Sun, J., Liang, Y., Marsh, J. F., Harris, J. M., and Oldroyd, G. E. 2008. Abscisic acid coordinates nod factor and cytokinin signaling during the regulation of nodulation in Medicago truncatula. Plant Cell 20:2681-2695.

Fähraeus, G. 1957. The infection of clover root hairs by nodule bacteria studied by a simple glass slide technique. J. Gen. Microbiol. 16:374-381.

Galibert, F., Finan, T. M., Long, S. R., Puhler, A., Abola, P., Ampe, F., Barloy-Hubler, F., Barnett, M. J., Becker, A., Boistard, P., Bothe, G., Boutry, M., Bowser, L., Buhrmester, J., Cadieu, E., Capela, D., Chain, P., Cowie, A., Davis, R. W., Dreano, S., Federspiel, N. A., Fisher, R. F., 
Gloux, S., Godrie, T., Goffeau, A., Golding, B., Gouzy, J., Gurjal, M., Hernandez-Lucas, I., Hong, A., Huizar, L., Hyman, R. W., Jones, T., Kahn, D., Kahn, M. L., Kalman, S., Keating, D. H., Kiss, E., Komp, C., Lelaure, V., Masuy, D., Palm, C., Peck, M. C., Pohl, T. M., Portetelle, D., Purnelle, B., Ramsperger, U., Surzycki, R., Thebault, P., Vandenbol, M., Vorholter, F. J., Weidner, S., Wells, D. H., Wong, K., Yeh, K. C., and Batut, J. 2001. The composite genome of the legume symbiont Sinorhizobium meliloti. Science 293:668-672.

Gleason, C., Chaudhuri, S., Yang, T., Muñoz, A., Poovaiah, B. W., and Oldroyd, G. E. 2006. Nodulation independent of rhizobia induced by a calcium-activated kinase lacking autoinhibition. Nature 441:1149-1152.

Hirsch, S., Kim, J., Muñoz, A., Heckmann, A. B., Downie, J. A., and Oldroyd, G. E. 2009. GRAS proteins form a DNA binding complex to induce gene expression during nodulation signaling in Medicago truncatula. Plant Cell 21:545-557.

Jefferson, R. A., Kavanagh, T. A., and Bevan, M. W. 1987. GUS fusions: $\beta$-glucuronidase as a sensitive and versatile gene fusion marker in higher plants. EMBO J. 6:3901-3907.

Jiménez-Zurdo, J. I., Mateos, P. F., Dazzo, F. B., and Martínez-Molina, E. 1996. Cell-bound cellulase and polygalacturonase production by Rhizobium and Bradyrhizobium species. Soil Biol. Biochem. 28:917-921.

Jones, K. M., Kobayashi, H., Davies, B. W., Taga, M. E., and Walker, G. C. 2007. How rhizobial symbionts invade plants: The SinorhizobiumMedicago model. Nat. Rev. Microbiol. 5:619-633.

Journet, E. P., El-Gachtouli, N., Vernoud, V., de Billy, F., Pichon, M., Dedieu, A., Arnould, C., Morandi, D., Barker, D. G., and GianinazziPearson, V. 2001. Medicago truncatula ENOD11: A novel RPRP-encoding early nodulin gene expressed during mycorrhization in arbusculecontaining cells. Mol. Plant-Microbe Interact 14:737-748.

Kaló, P., Gleason, C., Edwards, A., Marsh, J., Mitra, R. M., Hirsch, S., Jakab, J., Sims, S., Long, S. R., Rogers, J., Kiss, G. B., Downie, J. A., and Oldroyd, G. E. 2005. Nodulation signaling in legumes requires NSP2, a member of the GRAS family of transcriptional regulators. Science 308: 1786-1789.

Lévy, J., Bres, C., Geurts, R., Chalhoub, B., Kulikova, O., Duc, G., Journet, E. P., Ané, J. M., Lauber, E., Bisseling, T., Dénarié, J., Rosenberg, C., and Debellé, F. 2004. A putative $\mathrm{Ca}^{2+}$ and calmodulin-dependent protein kinase required for bacterial and fungal symbioses. Science 303:1361-1364.

Mateos, P. F., Baker, D. L., Petersen, M., Velázquez, E., Jiménez-Zurdo, J. I., Martínez-Molina, E., Squartini, A., Orgambide, G., Hubbell, D. H., and Dazzo, F. B. 2001. Erosion of root epidermal cell walls by Rhizobium polysaccharide-degrading enzymes as related to primary host infection in the Rhizobium-legume symbiosis. Can. J. Microbiol. 47:475-487.

Mateos, P. F., Jiménez-Zurdo, J. I., Chen, J., Squartini, A. S., Haack, S. K., Martínez-Molina, E., Hubbell, D. H., and Dazzo, F. B. 1992. Cellassociated pectinolytic and cellulolytic enzymes in Rhizobium leguminosarum biovar trifolii. Appl. Environ. Microbiol. 58:1816-1822.

Mitra, R. M., Gleason, C. A., Edwards, A., Hadfield, J., Downie, J. A., Oldroyd, G. E., and Long, S. R. 2004. A Ca ${ }^{2+} /$ calmodulin-dependent protein kinase required for symbiotic nodule development: Gene identification by transcript-based cloning. Proc. Natl. Acad. Sci. U.S.A. 101:4701-4705.

Miwa, H., Sun, J., Oldroyd, G. E., and Downie, J. A. 2006. Analysis of calcium spiking using a cameleon calcium sensor reveals that nodulation gene expression is regulated by calcium spike number and the developmental status of the cell. Plant J. 48:883-894.

Muñoz, J. A., Coronado, C., Pérez-Hormaeche, J., Kondorosi, A., Ratet, P., and Palomares, A. J. 1998. MsPG3, a Medicago sativa polygalacturonase gene expressed during the alfalfa-Rhizobium meliloti interaction. Proc. Natl. Acad. Sci. U.S.A. 95:9687-9692.

Oldroyd, G. E. 2013. Speak, friend, and enter: Signalling systems that promote beneficial symbiotic associations in plants. Nat. Rev. Microbiol. 11:252-263.

Oldroyd, G. E., and Downie, J. A. 2008. Coordinating nodule morphogenesis with rhizobial infection in legumes. Annu. Rev. Plant Biol. 59:519546.
Oldroyd, G. E., Murray, J. D., Poole, P. S., and Downie, J. A. 2011. The rules of engagement in the legume-rhizobial symbiosis. Annu. Rev. Genet. 45:119-144.

Reeve, W., Chain, P., O’Hara, G., Ardley, J., Nandesena, K., Bräu, L., Tiwari, R., Malfatti, S., Kiss, H., Lapidus, A., Copeland, A., Nolan, M., Land, M., Hauser, L., Chang, Y. J., Ivanova, N., Mavromatis, K., Markowitz, V., Kyrpides, N., Gollagher, M., Yates, R., Dilworth, M., and Howieson, J. 2010. Complete genome sequence of the Medicago microsymbiont Ensifer (Sinorhizobium) medicae strain WSM419. Stand. Genomic Sci. 2:77-86.

Robledo, M., Jiménez-Zurdo, J. I., Soto, M. J., Velázquez, E., Dazzo, F., Martínez-Molina, E., and Mateos, P. F. 2011. Development of functional symbiotic white clover root hairs and nodules requires tightly regulated production of rhizobial cellulase CelC2. Mol. Plant-Microbe Interact 24:798-807.

Robledo, M., Jiménez-Zurdo, J. I., Velázquez, E., Trujillo, M. E., ZurdoPiñeiro, J. L., Ramírez-Bahena, M. H., Ramos, B., Díaz-Mínguez, J. M., Dazzo, F., Martínez-Molina, E., and Mateos, P. F. 2008. Rhizobium cellulase CelC2 is essential for primary symbiotic infection of legume host roots. Proc. Natl. Acad. Sci. U.S.A. 105:7064-7069.

Robledo, M., Rivera, L., Jiménez-Zurdo, J. I., Rivas, R., Dazzo, F., Velázquez, E., Martínez-Molina, E., Hirsch, A. M., and Mateos, P. F. 2012. Role of Rhizobium endoglucanase CelC2 in cellulose biosynthesis and biofilm formation on plant roots and abiotic surfaces. Microb. Cell Fact. 11:125.

Robledo, M., Velázquez, E., Ramírez-Bahena, M. H., García-Fraile, P., Pérez-Alonso, A., Rivas, R., Martínez-Molina, E., and Mateos, P. F. 2011 b. The celC gene, a new phylogenetic marker useful for taxonomic studies in Rhizobium. Syst. Appl. Microbiol. 34:393-399.

Rodríguez-Llorente, I. D., Pérez-Hormaeche, J., Dary, M., Caviedes, M. A., Kondorosi, A., Ratet, P., and Palomares, A. J. 2003. Expression of MsPG3-GFP fusions in Medicago truncatula'hairy roots' reveals preferential tip localization of the protein in root hairs. Eur. J. Biochem. 270:261-269.

Sambrook, J., Fritsch, E. F., and Maniatis, T. 1989. Molecular Cloning: A Laboratory Manual. Cold Spring Harbor Laboratory, Cold Spring Harbor, N.Y., U.S.A.

Shaw, S. L., and Long, S. R. 2003. Nod factor elicits two separable calcium responses in Medicago truncatula root hair cells. Plant Physiol. 131: 976-984.

Sieberer, B. J., Chabaud, M., Fournier, J., Timmers, A. C., and Barker, D. G. 2012. A switch in $\mathrm{Ca}^{2+}$ spiking signature is concomitant with endosymbiotic microbe entry into cortical root cells of Medicago truncatula. Plant J. 69:822-830.

Smit, G., Kijne, J. W., and Lugtenberg, B. J. 1987. Involvement of both cellulose fibrils and a $\mathrm{Ca}^{2+}$-dependent adhesin in the attachment of Rhizobium leguminosarum to pea root hair tips. J. Bacteriol. 169:42944301.

Somasegaran, P., and Hoben, H. J. 1994. Handbook for Rhizobia: Methods in Legume-Rhizobium Technology. Springer-Verlag, New York.

Tian, Y., Liu, W., Cai, J., Zhang, L. Y., Wong, K. B., Feddermann, N., Boller, T., Xie, Z. P., and Staehelin, C. 2013. The nodulation factor hydrolase of Medicago truncatula: Characterization of an enzyme specifically cleaving rhizobial nodulation signals. Plant Physiol. 163: 1179-1190.

Wais, R. J., Keating, D. H., and Long, S. R. 2002. Structure-function analysis of nod factor-induced root hair calcium spiking in Rhizobiumlegume symbiosis. Plant Physiol. 129:211-224.

Weidner, S., Becker, A., Bonilla, I., Jaenicke, S., Lloret, J., Margaret, I., Pühler, A., Ruiz-Sainz, J. E., Schneiker-Bekel, S., Szczepanowski, R., Vinardell, J. M., Zehner, S., and Göttfert, M. 2012. Genome sequence of the soybean symbiont Sinorhizobium fredii HH103. J. Bacteriol. 194: 1617-1618.

Xie, F., Murray, J. D., Kim, J., Heckmann, A. B., Edwards, A., Oldroyd, G. E., and Downie, J. A. 2012. Legume pectate lyase required for root infection by rhizobia. Proc. Natl. Acad. Sci. U.S.A. 109:633-638. 